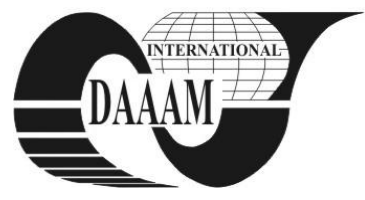

Annals of DAAAM for 2011 \& Proceedings of the 22nd International DAAAM Symposium, Volume 22, No. 1, ISSN 1726-9679 ISBN 978-3-901509-83-4, Editor B. Katalinic, Published by DAAAM International, Vienna, Austria, EU, 2011 Make Harmony between Technology and Nature, and Your Mind will Fly Free as a Bird Annals \& Proceedings of DAAAM International 2011

\title{
EXPERIMENTAL RESULTS FOR LASER CUTTING OF STAINLESS STEEL PLATE 5 MM IN THICKNESS
}

\author{
BABALOVA, E[va]; TARABA, B[ohumil]; BEHULOVA, M[aria] \& SPANIELKA, J[an]
}

\begin{abstract}
Article deals with the temperature measurement and analysis of temperature fields by the process of laser cutting. A direct path was carried out during experiments on a stainless steel plate of $5 \mathrm{~mm}$ in thickness. The temperatures were measured by four K-type thermocouples using digital converter NI USB9211 in order to find out the temperature distribution in the direction perpendicular to the central plane of the cut. Moreover, the dimension of the kerf width was determined using confocal laser scanning microscopy. Obtained results of temperature measurements will be used for verification of developed simulation model and results of numerical simulation of laser cutting process obtained by ANSYS and SYSWELD software.
\end{abstract}

Key words: laser cutting, stainless steel, temperature measurement, kerf width

\section{INTRODUCTION}

Nowdays, laser cutting is an important industrial process used for cutting all types of materials. Laser cutting has wide application in the field of automotive industry. Practically all bodywork components in the car sectors are cut by lasers (Cekic et al., 2009). High productivity and quality of components produced by laser cutting are of particular interest to manufacturers (Begic et al., 2009). Continuous-wave CW $\mathrm{CO}_{2}$ laser is most often used for this application but Nd: YAG laser is preferred in cases that require narrow kerf width and small HAZ width. For many years laser cutting technology has been used in industry because of its accuracy and efficiency. Industrial users have obtained a lot of experience necessary for the use of the various laser parameters. The assist gas type and pressure have strong influence on the quality of produced cuts. Based on the investigation of the effect of oxygen and nitrogen as assist gases on the cut quality of austenitic stainless steel plate it was found that nitrogen gas produces brighter and smoother cut surface with smaller kerf width compared to oxygen. The assist gas is responsible for removing the molten metal from the cut kerfs, and it protects laser optics from being damaged by the resulting ejected spatters (Salem et al., 2008). Next step - numerical simulation is a creative process (Necas, Taraba, 2010). The numerical simulation of laser cutting process will be carried out using the solution of an inverse heat transfer problem (Alifanov, 1994).

\section{OBJECTIVES}

The aim of article is the temperature measurement and analysis of temperature fields during laser cutting of the plate from austenitic stainless steel with the thickness of $5 \mathrm{~mm}$. The obtained temperatures will be used for the verification of results of numerical simulation of the laser cutting process using ANSYS and SYSWELD software. Microstructure of stainless steel plate before and after laser cutting process was observed by optical microscopy. The kerf width was measured using confocal laser scanning microscopy.

\section{EXPERIMENTAL PROCEDURE}

Laser cutting experiments were performed at the Vienna University of Technology. During experiments, plates from stainless steel DIN 1.4301 (X5CrNi18-10) were cut. The main aim of experiments was to find out the transverse temperature distribution. For this purpose, five samples with dimensions of 200x100x5 mm were prepared. Each sample had attached two thermocouples (TC) from the left side and two TC from the right side. The distance of TC from the central plane of the cut was different for each sample. For example, the location of two TC at $2 \mathrm{~mm}$ and $5.4 \mathrm{~mm}$ from the central plane of the cut is shown in Fig. 1.

Chronel-alumel thermocouples of " $K$ " type applicable within the temperature range up to $1250{ }^{\circ} \mathrm{C}$ were used. They were placed to the holes with diameter of $2.0 \mathrm{~mm}$ and attached to samples by micro-welds.

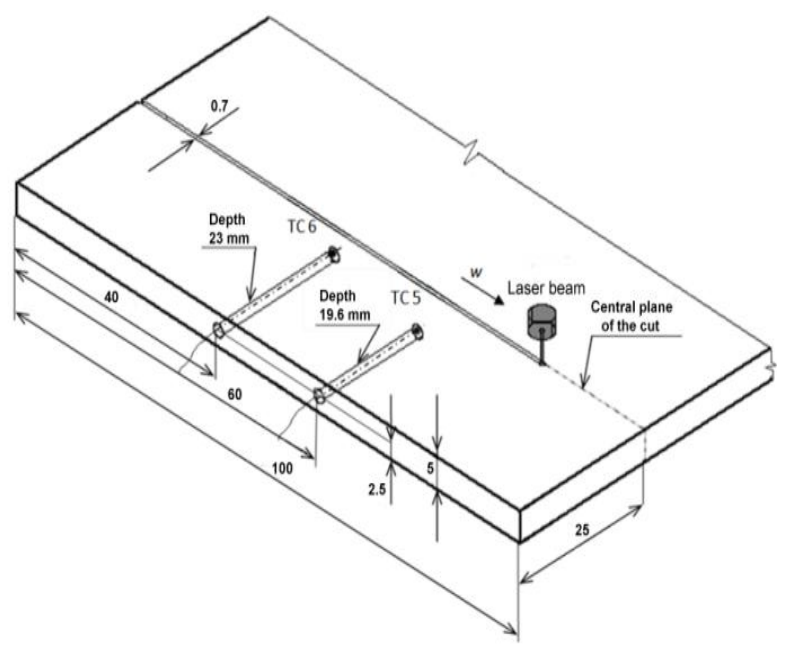

Fig. 1. The placement of thermocouples for transverse temperature measurement

The experimental equipment consisted of a cutting machine CW: $\mathrm{CO}_{2}$ OERLIKON Precision Laser CH-1196 Gland, 25 KVA, $10600 \mathrm{~nm}, 2000 \mathrm{~W}$, nitrogen $\mathrm{N}_{2}$ as assist gas, sample, connecting cables, module NI USB 9211 and personal computer (Fig. 2).

The system of thermocouples was connected through input module NI USB $9211(* * *, 2010)$ to the portable personal computer. Electric recording method for temperature measurement was applied. Temperatures were recorded 5 times per second. The obtained temperatures were processed using the Origin 8 software.

For experiments, following cutting parameters were used: pressure of assist gas - $13 \mathrm{bar}$, cutting speed $-0.7 \mathrm{~m} . \mathrm{min}^{-1}$, nozzle to material distance $-0.8 \mathrm{~mm}$ and laser power $-1.6 \mathrm{~kW}$. It was necessary to keep the same cutting parameters for all samples. 


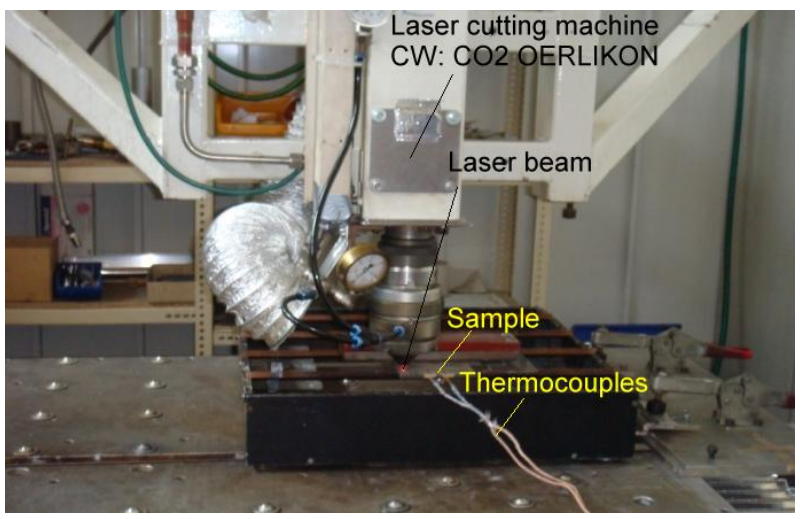

Fig. 2. Laser cutting device

\section{RESULTS OF EXPERIMENTS}

Temperature distributions in the test samples for searching of transverse temperature distribution along a plane cut were obtained. Fig. 3 illustrates the time history of temperatures measured by thermocouples in six selected positions: at the distance of $2.10 \mathrm{~mm} ; 2.20 \mathrm{~mm} ; 2.45 \mathrm{~mm} ; 2.50 \mathrm{~mm} ; 5.40 \mathrm{~mm}$ and $2.00 \mathrm{~mm}$ from the central plane of the cut. The records of measured temperatures are graphically processed together in order to visualize assumed quasi steady-state temperature field.

The highest measured temperature was $229^{\circ} \mathrm{C}$ on TC6 at the distance of $2.00 \mathrm{~mm}$, the lowest measured temperature was $68{ }^{\circ} \mathrm{C}$ on TC5 at the distance of $5.40 \mathrm{~mm}$ from central plane of the cut. Measured temperature gradually decreases with the increased distance of the thermocouple from central plane of the cut.

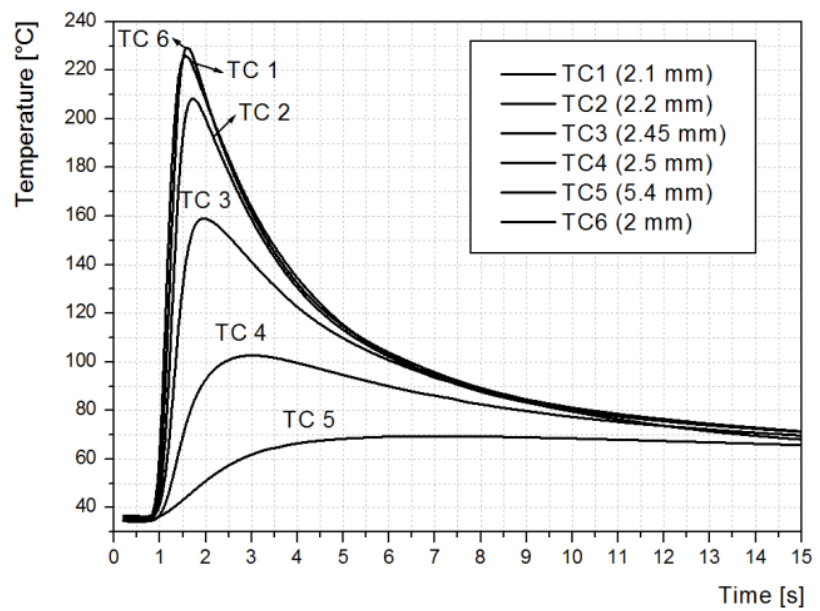

Fig. 3. Time history of temperatures measured by selected thermocouples.

The kerf width was measured by confocal laser scanning microscopy (Fig. 4). The average size of the kerf width was $0.7327 \mathrm{~mm}$ (Fig. 5).

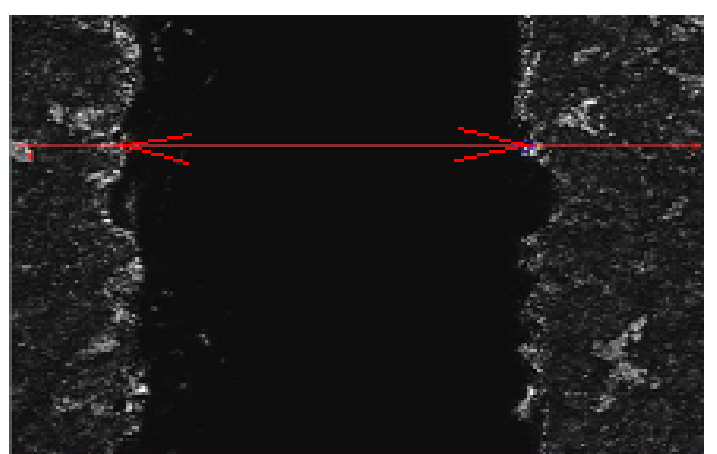

Fig. 4. Kerf width measured by confocal laser scanning microscopy

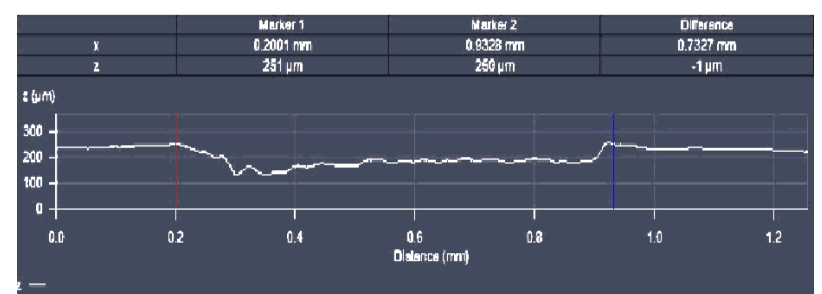

Fig. 5. Measured kerf width

\section{DISCUSSION AND CONCLUSION}

The temperature measurements during laser cutting were performed using five samples from stainless steel. At the distance of $2 \mathrm{~mm}$ from the cutting plane, the maximum temperature only $229^{\circ} \mathrm{C}$ was measured. Consequently, the HAZ is very near. The average kerf width was found to be $0.7327 \mathrm{~mm}$.

In the next step, measured temperatures will be used for the numerical simulation of laser cutting using ANSYS and SYSWELD software in two ways. Using the solution of inverse problem and the inverse-numerical-correlation (INC) method (Alifanov, 1994), the unknown parameters and characteristics of laser heat source will be determined. In addition, the measured temperatures will be applied for the verification of developed simulation model included nonlinear thermophysical material properties and boundary conditions. Based on this model, the process of laser cutting will be analyzed in details with the aim to optimize parameters of laser cutting.

\section{ACKNOWLEDGEMENTS}

The research was supported by the VEGA MŠ SR and SAV within the project VEGA 1/1041/11 and EU projects ITMS: 26220120014 and ITMS: 26220120048. Authors thank to the institutions MTF STU and TU Wien for facilitating implementation of research.

\section{REFERENCES}

Alifinov M., A. (1994). Inverse heat transfer problems. Springer-Verlag, New York London Tokyo, 1994. ISBN 3540-53679-5

Begic D., Kulenovic M., Cekic A \& Bliedtner J. (2009). CW $\mathrm{CO}_{2}$ Laser cutting of tungsten alloy using $\mathrm{O}_{2}$ Assist gas. Proceedings of the $20^{\text {th }}$ International DAAAM Symposium, 2009, Vienna, ISSN 1726-9679, ISBN 978-3-901509-70-4, Editor B. Katalinic, pp. 1345-1346, Published by DAAAM International, Vienna, Austria, EU

Cekic A., Kulenovic M., Begic D \& Bliedtner J. (2009). Investigation of optimum condition in laser cutting of alloy steel 1.4571 using air assist gas. Proceedings of the $20^{\text {th }}$ International DAAAM Symposium, 2009, Vienna, ISSN 1726-9679, ISBN 978-3-901509-70-4, Editor B. Katalinic, pp. 1347-13468, Published by DAAAM International, Vienna, Austria, EU

Necas D., Taraba B. (2010). Systematic approach towards the computer modelling of chosen forming technological process. Proceedings of International doctoral seminar, May 16-19, 2010, Smolenice castle, ISBN 978-80-8096118-3, Editor Alena Sučáková, pp. 367-375, Published by AlumniPress, Faculty of materials Science and technology, Trnava, Slovakia, EU

Salem H. G., Mansour M. S., Badr Y \& Abbas W. A. (2008). CW Nd: YAG laser cutting of ultra low carbon steel thin sheets using $\mathrm{O}_{2}$ assist gas. Journal of materials processing technology. 196, (2008), pp. 64-72

*** (2010) Input module NI USB9211, http://sine.ni.com/ nips/cds/view/p/lang/en/nid/13880 